\title{
Trans-fatty acids induce pro-inflammatory responses and endothelial cell dysfunction
}

\author{
Kevin A. Harvey ${ }^{1}$, Tyler Arnold ${ }^{1}$, Tamkeen Rasool ${ }^{1}$, Caryl Antalis ${ }^{1}$, Steven J. Miller ${ }^{2}$ \\ and Rafat A. Siddiqui ${ }^{1,3,4 *}$ \\ ${ }^{1}$ Cellular Biochemistry Laboratory, Methodist Research Institute, Clarian Health, \\ 1701 N. Senate - Room E504, Indianapolis, IN 46202, USA \\ ${ }^{2}$ Department of Surgery, Indiana University School of Medicine, Indianapolis, IN, USA \\ ${ }^{3}$ Department of Biology, Indiana University-Purdue University, Indianapolis, IN, USA \\ ${ }^{4}$ Department of Medicine, Indiana University School of Medicine, Indianapolis, IN, USA \\ (Received 19 January 2007 - Revised 13 July 2007 - Accepted 16 July 2007)
}

Epidemiological data indicate that there is a strong association between intake of trans-18:2 fatty acids (TFA) and sudden cardiac death. There is little known about the mechanisms by which TFA exert harmful effects on the cardiovascular system. The present in vitro study is the first to demonstrate the effects of membrane-incorporated C18:2 TFA on human aortic endothelial cell (HAEC) function. Trans-18:2 fatty acids were incorporated to a greater extent (2-fold) in the phospholipid fraction of endothelial cells than that of cis-18:2; furthermore, these fatty acids were enriched to a similar extent in the TAG fraction. Flow cytometric analysis indicated that TFA treatment of HAEC significantly increased the expression of endothelial adhesion molecules, including intercellular adhesion molecule-1 (CD54) and vitronectin receptor (CD51/CD61). Incorporation of TFA into membranes increased HAEC adhesion to fibronectin- or vitronectin-coated plates by 1.5- to 2-fold, respectively. Neutrophil and monocyte adhesion to HAEC monolayers was nearly proportional to adhesion molecule expression. TFA treatment also induced the release of monocyte chemoattractant protein- 1 by nearly 3 -fold in non-stimulated HAEC. Furthermore, we examined the role of TFA on in vitro angiogenic assays. Chemotactic migration of TFA-treated HAEC toward sphingosine-1-phosphate (SPP) was significantly increased compared with controls. Conversely, capillary morphogenesis of TFA-treated HAEC was significantly inhibited in response to SPP, suggesting that TFA incorporation suppresses endothelial cell differentiation. In conclusion, these in vitro studies demonstrated that TFA play a role in the induction of pro-inflammatory responses and endothelial cell dysfunction.

Endothelial cells: Trans-fatty acids: Adhesion molecules: Chemotaxis: Capillary morphogenesis

After the first successful hydrogenation of oils in 1897, the proportional intake of trans isomers of unsaturated fatty acids has dramatically risen in the human $\operatorname{diet}^{1}$. Trans-fatty acid consumption is estimated to contribute $4-12 \%$ of the total dietary fat intake in the US population, which corresponds to $13 \mathrm{~g}$ trans-fatty acids/person per $\mathrm{d}$ at the higher intake $^{2}$. Unlike Western diets, traditional diets in Korea and Japan contain relatively small quantities of trans-fatty acids, with estimates in the range of $0 \cdot 1-0.6 \mathrm{~g} /$ person per $\mathrm{d}^{3}$. Trans-fatty acids occur naturally at relatively low levels in meat and dairy products as a by-product of fermentation in ruminant animals ${ }^{1}$. The majority of trans-fatty acids in the diet are trans- $8: 1$, which is derived from the partial hydrogenation of oils ${ }^{4}$. However, the process of heating vegetable oils during deodorisation, and frying or baking food in vegetable oils results in the generation of trans-18:2 $2^{5}$. The elevated temperature in these processes causes the conversion of $c$ is double bonds to trans isomers.
The effect of increased trans-fatty acid consumption has been linked to a variety of afflictions, most notably CHD. Numerous epidemiological studies have correlated elevated dietary intake of trans-fatty acids with increased morbidity and mortality from CHD. Willett suggested that replacing partially hydrogenated fat with natural non-hydrogenated vegetable oils could prevent 30000-100000 CHD-related premature deaths each year ${ }^{6}$. By evaluating fatty acid intake and mortality over 25 years, the Seven Countries Study reported a correlation between trans-fatty acid consumption and the risk of death from CHD $(r 0.78 ; P<0.001)^{7}$. Similar findings were also reported in the Health Professionals Follow-up Study ${ }^{8}$, the Alpha-tocopherol Beta-carotene Cancer Prevention Study ${ }^{9}$ and the Nurses' Health Study ${ }^{10}$. A Danish study also linked trans-fatty acid consumption to the development of atherosclerosis ${ }^{11}$.

Compared with the consumption of an equal amount of energy from saturated or cis-unsaturated fats, the consumption

Abbreviations: EBM-2, endothelial cell basal medium-2; HAEC, human aortic endothelial cells; MCP-1, monocyte chemoattractant protein-1; SPP, sphingosine-1phosphate.

* Corresponding author: Dr Rafat Siddiqui, fax +1 317962 9369, email rsiddiqu@ clarian.org 
of trans-fatty acids raises levels of LDL-cholesterol, reduces levels of HDL-cholesterol and increases the total cholesterol:HDL-cholesterol ratio, a powerful predictor of the risk of $\mathrm{CHD}^{12}$. Although these effects would be expected to increase the risk of $\mathrm{CHD}$, the relationship between the intake of transfats and the incidence of CHD reported in prospective studies has been greater than that predicted by changes in serum lipid levels alone ${ }^{13-15}$, suggesting that trans-fatty acids may also influence other risk factors for CHD.

Recent studies suggest multiple possible mechanisms that might mediate the association of trans-fatty acids with $\mathrm{CVD}^{16}$. For example, trans-fatty acids influence PG balance, which in turn promotes thrombogenesis ${ }^{17}$ and inhibits the conversion of linoleic acid to arachidonic acid and to other $n-6$ PUFA, perturbing essential fatty acid metabolism and causing changes in the phospholipid fatty acid composition in the aorta $^{18}$. Trans-fatty acids have been associated with the activation of systemic inflammatory responses, including substantially increased levels of IL-6, TNF- $\alpha$, TNF receptors and monocyte chemoattractant protein-1 (MCP-1) ${ }^{19}$. Furthermore, trans-fatty acids have been associated with increased levels of several markers of endothelial activation, including soluble intercellular adhesion molecule 1, soluble vascular-cell adhesion molecule 1 and E-selectin ${ }^{20}$. Trans-fatty acids are postulated to be involved in promoting vascular dysfunction, as reflected by a reduction in brachial artery flow ${ }^{21}$. These observations suggest that trans-fatty acids are linked to the development of CHD, probably via a vascular pro-inflammatory response.

Although there is strong epidemiological evidence implicating elevated trans-fatty acid consumption in the development of CHD, the extent and manner in which trans-fatty acids affect the vasculature remain largely unknown. Clearly, vascular endothelial cells play a vital role in the development and progression of atherogenesis. In the present study, we initiated in vitro studies to determine the direct effects of trans-fatty acid supplementation on the phenotypic and functional consequences in HAEC. We hypothesised that trans-fatty acid incorporation would induce a pro-inflammatory response leading to altered cell function.

\section{Materials and methods}

\section{Materials}

Chemicals and reagents were purchased from Sigma Chemical Company (St Louis, MO, USA), unless otherwise noted. Growth factor-reduced Matrigel matrix and antibodies coupled with fluorescent labels were purchased from Becton Dickinson (Bedford, MA, USA). Consumable tissue culture materials and Transwell inserts were acquired from Fisher Scientific (Pittsburgh, PA, USA). Sphingosine-1-phosphate (SPP) was purchased from Calbiochem (La Jolla, CA, USA). The protein growth factors utilised in the present study and the MCP-1 ELISA kits were acquired from $\mathrm{R}$ \& D Systems, Inc. (Minneapolis, MN, USA). Human-derived aortic endothelial cells as well as the EGM-2MV Bullet kits (endothelial growth medium-2 microvascular) were purchased from Cambrex (East Rutherford, NJ, USA). All fatty acids were acquired from $\mathrm{Nu}-\mathrm{Chek}$ Prep Incorporated (Elysian, MN, USA).

\section{Human aortic endothelial cell culture}

A primary cell line derived from HAEC was maintained in endothelial cell basal medium-2 (EBM-2) containing 5\% fetal bovine serum and the bullet kit materials as specified by the manufacturer. Cells were maintained at $37^{\circ} \mathrm{C}$ in a humidified atmosphere in the presence of $5 \% \mathrm{CO}_{2}$. Only endothelial cell cultures of less than ten passages and $80-90 \%$ confluence were utilised in the present study.

\section{Fatty acid incorporation into the endothelial cells}

Stock solutions ( $1 \mathrm{mM}$ ) of fatty acids (cis-18:2, linoleic acid; trans-18:2, linoelaidic acid) were prepared by complexing with fatty acid-free bovine serum albumin ${ }^{22}$. Sub-confluent endothelial cells were cultured for $24 \mathrm{~h}$ in EBM-2 complete media either in the presence or absence of $25 \mu \mathrm{M}$-cis-18:2 or -trans-18:2 fatty acid. This concentration of fatty acids was found to be optimum by time- and dose-dependent assessment of fatty acid effect on cell growth and morphology (data not shown). After incubation, the cells were trypsinised and repeatedly washed in PBS $(\mathrm{Ca}$ and $\mathrm{Mg}$ free) containing $1 \%$ bovine serum albumin to ensure removal of NEFA. Lipids were extracted with chloroform-methanol $(2: 1, \mathrm{v} / \mathrm{v})$ using the Folch method ${ }^{23}$. The lipid extracts were further fractionated into phospholipids, TAG and cholesteryl esters by TLC using a solvent system (hexane-diethyl ether-acetic acid, 70:30:1, by vol.). The lipid fractions were scraped from the TLC plate and subjected to acid-catalysed esterification by heating at $100^{\circ} \mathrm{C}$ for $90 \mathrm{~min}$ in a boron trifluoridemethanol solution $(14 \%)$. The methyl esters of fatty acids were separated on a GC system (Shimadzu GC2010; Shimadzu, Columbia, MD, USA) equipped with an Rt 2560 column $(100 \mathrm{~m} ; 0.25 \mathrm{~mm}$ internal diameter; $0.2 \mu \mathrm{m})$. The oven temperature was ramped from $100^{\circ} \mathrm{C}$ ( 4 min hold) to $240^{\circ} \mathrm{C}$ at $3^{\circ} \mathrm{C} / \mathrm{min}(10 \mathrm{~min}$ hold $)$ with a flame ionisation detector at $250^{\circ} \mathrm{C}$. Fatty acid peaks were identified by retention time in comparison with authentic standards (Restek Corp., Bellefonte, PA, USA). Areas of identified peaks from 14:0 to $22: 6 n-3$ were summed and individual fatty acids are expressed as area percentage of total identified peak areas. Data were analysed with Shimadzu's GC solutions software (Columbia, MD, USA).

\section{Flow cytometric analysis of adhesion molecule expression}

Trypsinised endothelial cells $\left(1 \times 10^{5} /\right.$ sample $)$ were washed in PBS containing $0.5 \%$ bovine serum albumin and re-suspended into a volume of $100 \mu \mathrm{l}$ of this labelling buffer. Cells were labelled with $0.25 \mu \mathrm{g}$ phycoerythrin-conjugated antibody for 20 min; subsequently, the cells were washed twice in PBS containing $0.5 \%$ bovine serum albumin. An isotype control was established for each sample set to ensure specificity of the antibody binding. Analysis was performed on a FACSCalibur flow cytometer (Becton Dickinson, San Jose, CA, USA) equipped with an air-cooled Ar laser emitting at a $488 \mathrm{~nm}$ wavelength. Fluorescence was detected through a $575 \pm 26$ band pass filter and quantified using CellQuest Software (Becton Dickinson). Results indicate the mean fluorescent intensity of gated endothelial cells, which excluded cellular debris and particles. 
Endothelial cell adhesion to basement membrane components

HAEC $\left(1 \times 10^{4}\right)$ cultured with fatty acids, as described above, were placed onto fibronectin $\left(5 \mu \mathrm{g} / \mathrm{cm}^{2}\right)$ or vitronectin $(1 \mu \mathrm{g} /$ $\mathrm{cm}^{2}$ ) coated twenty-four-well plates. Cells were incubated for $30 \mathrm{~min}$ at $37^{\circ} \mathrm{C}$. Aspirating cells from the wells terminated the assay; subsequently, the remaining non-adherent cells were removed by washing three times in PBS $(\mathrm{Ca}$ and $\mathrm{Mg}$ free). The adherent cells were fixed in a $5 \%$ formaldehyde solution. Adhesion was quantified by enumerating the average number of cells observed within random fields of view $(200 \times)$.

\section{Leucocyte adhesion to endothelial cell monolayers}

Leucocytes were isolated from normal human peripheral blood in compliance with institutional guidelines. Neutrophil leucocytes were selected by means of density gradient centrifugation using the Ficoll-Hypaque technique as previously described $^{24}$. Monocytes were enriched on a Ficoll-Hypaque gradient before a second density gradient centrifugation step using a 1:1 isosmotic Percoll solution with PBS-citrate $\left(\mathrm{NaH}_{2} \mathrm{PO}_{4}, 1.49 \mathrm{mM} ; \mathrm{Na}_{2} \mathrm{HPO}_{4}, 9.15 \mathrm{~mm} ; \mathrm{NaCl}, 140 \mathrm{~mm}\right.$; $\mathrm{C}_{6} \mathrm{H}_{5} \mathrm{Na}_{3} \mathrm{O}_{7} .2 \mathrm{H}_{2} \mathrm{O}, 13 \mathrm{~mm} ; \mathrm{pH} 7 \cdot 2$ ) as previously described ${ }^{25}$. The leucocytes were washed twice in Hanks balanced salt solution and re-suspended to a concentration of $1 \times 10^{5}$ cells $/ \mathrm{ml}$. HAEC were grown with cis-18:2 or trans-18:2 fatty acids in twenty-four-well tissue plates to near confluency before use. Cells were washed to remove fatty acids, and neutrophils or monocytes $\left(1 \times 10^{4}\right)$ were loaded onto the endothelial cell monolayers and maintained at $37^{\circ} \mathrm{C}$ for $30 \mathrm{~min}$. Non-adherent cells were aspirated from the wells. To ensure the removal of remnant non-adherent cells, the monolayers were washed three times with Hank's balanced salt solution followed by fixation of adherent cells in a $5 \%$ formaldehyde solution. Adhesion to the endothelial cells was quantified by enumerating the average number of leucocytes observed within random fields of view $(200 \times)$ by at least two blinded observers. Samples were assayed in quadruplicate.

\section{Monocyte chemoattractant protein-1 analysis by enzyme-} linked immunosorbent assay

MCP-1 released from endothelial cells into the culture media was quantified using a Quantikine Human MCP-1 Immunoassay ELISA kit (R\&D Systems, Minneapolis, MN, USA) according to the manufacturer's guidelines.

\section{Endothelial cell migration assay}

Endothelial cell migration was performed as previously described $^{26}$. Briefly, harvested HAEC were washed in serum-free EBM-2 and re-suspended to a concentration of $1 \times 10^{6}$ cells $/ \mathrm{ml}$. Cells $\left(1 \times 10^{5}\right)$ were placed onto an $8 \mu \mathrm{m}$ Transwell chamber and incubated for $30 \mathrm{~min}$ at $37^{\circ} \mathrm{C}$ to permit anchoring to the filter. These inserts were placed into wells containing $300 \mu \mathrm{l}$ serum-free EBM-2 containing SPP to induce directed migration over a $4 \mathrm{~h}$ incubation. To halt the HAEC migration, cells were removed from the upper compartment and the migrated cells were fixed in a $5 \%$ formaldehyde solution. The cells were subsequently stained with 4',6-diamidino-2-phenylindole $(5 \mu \mathrm{g} / \mathrm{ml})$ to visualise the migrated cells. HAEC migration was quantified on a Leica inverted fluorescent microscope (model no. DMI4000B; Leica Microsystems, Wetzlar, Switzerland) by enumerating the average cell number in three randomly selected fields of view $(200 \times)$ on three separate filters ${ }^{27}$.

\section{In vitro endothelial cell capillary morphogenesis assay}

HAEC differentiation into capillary-like structures was accomplished using a two-dimensional Matrigel-based assay as previously described ${ }^{28}$. Briefly, cells $\left(3.5 \times 10^{4} /\right.$ well $)$ treated with cis-18:2 or trans-18:2 fatty acids were placed into Matrigel-coated twenty-four-well tissue culture plates. The cells were incubated in the absence or presence of angiogenic stimulants (hepatocyte growth factor or SPP) and maintained for $16 \mathrm{~h}$ at $37^{\circ} \mathrm{C}$ in the presence of $5 \% \mathrm{CO}_{2}$. Non-treated control samples were maintained in serum-free EBM-2 media. Capillary-like structures were examined microscopically $(40 \times)$ using an inverted Olympus CK40 microscope and random photomicrographs were taken. Quantification of the capillary-like structures was accomplished by enumerating the number of multi-cellular nodes as previously described $^{28,29}$. Each sample was assayed in triplicate and reproduced on at least three separate occasions.

\section{Statistical analysis}

Data are represented as mean values and standard deviations of at least three determinants. Statistical significance between datasets was determined using the Student's $t$ test. Overall tests were performed using ANOVA. Pairwise comparisons between groups were performed using Tukey's multiple comparison test. When a calculated $P$ value of less than 0.05 was observed, statistical significance is indicated.

\section{Results}

\section{Fatty acid incorporation}

Endothelial cells were cultured for $24 \mathrm{~h}$ in EBM-2 complete media either in the presence or absence of $25 \mu \mathrm{M}$-cis-18:2 or -trans-18:2 fatty acids. Both cis- and trans-fatty acids were incorporated in HAEC resulting in an increase in the total PUFA fraction, a corresponding decrease in the MUFA fraction and only a modest decrease in the SFA fraction (Fig. 1 (A)). Data presented in Fig. 1 (B) indicate that trans18:2 fatty acids incorporated more efficiently than the cis-fatty acid counterpart. The cellular content of trans-18:2 increased to 21.9 (SD 1.0) $\%$ of the fatty acid content in the presence of $25 \mu \mathrm{M}$-trans-18:2; however, a similar concentration of cis-18:2 resulted in an increase to 13.2 (SD 1.6) $\%$ of the cellular fatty acid content. We further analysed fatty acid content in the phospholipid, TAG and cholesteryl ester fractions of endothelial cells treated with cis-18:2 or trans $-18: 2$ fatty acids. Consistent with total cell homogenates, more trans-18:2 fatty acids were enriched in phospholipids than cis-18:2 fatty acids (cis-18:2 distribution: untreated, $1.9 \%$; cis-18:2-treated, $22.5 \%$; trans-18:2-treated, $1.2 \%$. Trans-18:2 distribution: untreated, $0 \%$; cis-18:2-treated, 0\%; trans-18:2-treated, 40.4\%). However, a similar level 

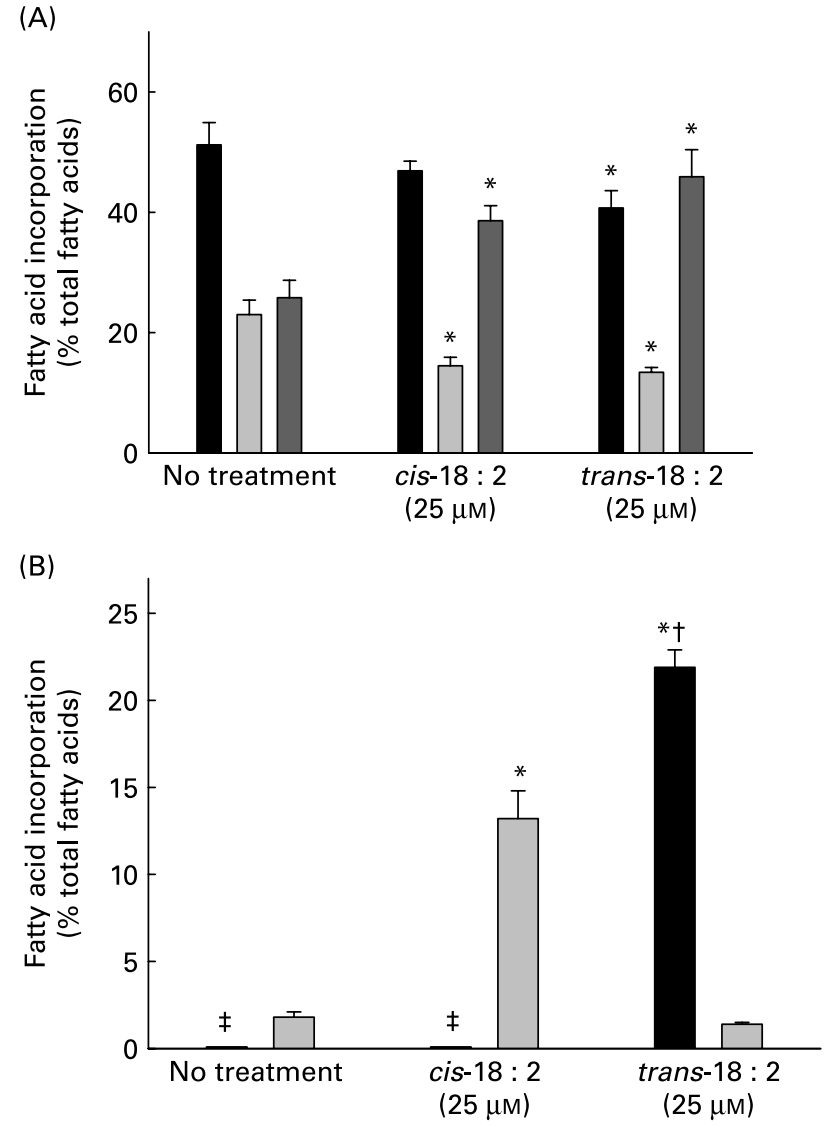

Fig. 1. Fatty acid composition of human aortic endothelial cells incorporated with cis- and trans-18:2 fatty acids. Sub-confluent endothelial cells were cultured for $24 \mathrm{~h}$ in endothelial cell basal medium-2 complete media in the presence or absence of fatty acid $(25 \mu \mathrm{M})$. Incorporation of fatty acids was analysed by GC (Shimadzu GC2010; Shimadzu, Columbia, MD, USA). (A) Distribution of the fatty acid classes in treated endothelial cells: SFA ( $\square$ ), MUFA ( $\square$ ), PUFA ( $\square$ ). (B) Relative incorporation of cis- ( $\square$ ) and trans-18:2 (匹) fatty acids into endothelial cells. Results are expressed as percentage composition. Data are means for at least three experiments, with standard deviations represented by vertical bars. Data were analysed by using ANOVA $(P<0.001)$ and Tukey's multiple comparison test. ${ }^{*}$ Mean value was significantly different from that of untreated endothelial cells $(P<0.05)$. † Mean value was significantly different from that of the cis-18:2-treated cells $(P<0.05)$. $\ddagger$ Non-detectable levels of trans-18:2.

of cis-18:2 and trans-18:2 enrichment was observed in the TAG fraction (cis-18:2 distribution: untreated, 2.2\%; cis18:2-treated, $16.7 \%$; trans-18:2-treated, $2 \cdot 1 \%$. Trans $-18: 2$ distribution: untreated, $0 \%$; cis-18:2-treated, $0 \%$; trans$18: 2$-treated, $16.7 \%$ ). No detectable amounts of cis-18:2 or trans $-18: 2$ were found in the cholesteryl ester fractions.

\section{Adhesion molecule expression on endothelial cells}

The relative expression of adhesion molecules, intercellular adhesion molecule-1 (CD54) and vitronectin receptor (CD51/CD61) was determined in HAEC after cis-18:2 and trans-18:2 treatment using flow cytometric analysis. Intercellular adhesion molecule-1 surface expression level (mean fluorescent intensity) was $32.8 \%$ higher in trans-18:2-treated cells (154.0 (SD 10.9)) compared with that of cis-18:2-treated cells (115.9 (SD 5.4)) (Table 1). Similarly, vitronectin receptor
Table 1. Fatty acid effects on endothelial cell inflammatory responsest (Mean values and standard deviations)

\begin{tabular}{|c|c|c|c|c|}
\hline \multirow[t]{2}{*}{ Treatment... } & \multicolumn{2}{|c|}{ cis-18:2 } & \multicolumn{2}{|c|}{ trans-18:2 } \\
\hline & Mean & SD & Mean & SD \\
\hline \multicolumn{5}{|c|}{ Adhesion molecule expression (mean fluorescent intensity) } \\
\hline ICAM-1 & $115 \cdot 9$ & $5 \cdot 4$ & $154 \cdot 0^{*}$ & $10 \cdot 9$ \\
\hline CD51/CD61 & 78.5 & $6 \cdot 9$ & $95 \cdot 6^{\star}$ & $4 \cdot 2$ \\
\hline \multicolumn{5}{|c|}{ Adhesion to matrix components (cells/200 $\times$ field of view) } \\
\hline Fibronectin & 41.5 & $4 \cdot 0$ & $70 \cdot 5^{\star}$ & $3 \cdot 7$ \\
\hline Vitronectin & 57.5 & 8.5 & $84 \cdot 3^{*}$ & $4 \cdot 3$ \\
\hline \multicolumn{5}{|c|}{ Adhesion to inflammatory cells (cells/200 × field of view) } \\
\hline Neutrophis & $20 \cdot 0$ & $7 \cdot 0$ & $58 \cdot 8^{*}$ & $11 \cdot 0$ \\
\hline Monocytes & $21 \cdot 3$ & $7 \cdot 5$ & $61 \cdot 3^{*}$ & $12 \cdot 5$ \\
\hline
\end{tabular}

ICAM-1, intercellular adhesion molecule-1.

${ }^{*}$ Mean value was significantly different from that of the cis-18:2-treated cells $(P<0.05)$.

†Assays were performed as described in the text. Data were analysed using Student's $t$ test between groups $(n 4)$.

(CD51/CD61) expression exhibited a $21.8 \%$ increase in the trans-18:2 fatty acid-treated endothelial cells (95.6 (SD 4.2)) compared with that of cis-18:2-treated cells (78.5 (SD 6.9)) (Table 1).

\section{Human aortic endothelial cell adhesion to basement membrane components}

After observing the increased expression levels of key endothelial adhesion molecules, fatty acid-incorporated HAEC were examined for their ability to bind preferentially to fibronectin- and vitronectin-coated wells. Compared with cis-18:2, trans-fatty acid-treated HAEC demonstrated a nearly 1.7 -fold increase in their ability to adhere to fibronectin (trans-18:2, 70.5 (SD 3.7) v. cis-18:2, 41.5 (SD 4.0); Table 1). Similarly, an approximately 1.5 -fold increase was observed in transfatty acid-treated HAEC adherence to vitronectin (Table 1).

\section{Leucocyte adhesion to human aortic endothelial cells}

Increased adhesion molecule expression on endothelial cells is often a key indicator of a pro-inflammatory state, which would result in a greater capacity for leucocyte tethering and subsequent binding and extravasation. We therefore isolated neutrophils and monocytes from normal peripheral blood to determine the effect of cis-18:2 and trans-18:2 fatty acid incorporation on leucocyte adherence to endothelial cell monolayers. Both neutrophils (trans-18:2, 58.8 (SD 11.0) $v$. cis-18:2, 20.0 (SD 7.0)) and monocytes (trans-18: 2, 61.3 (SD 12.5) v. cis-18:2, 21.3 (SD 7.5)) showed a nearly 3-fold greater adherence to trans-18:2-treated HAEC than that measured with cis-18:2-treated HAEC (Table 1).

\section{Monocyte chemoattractant protein-1 release}

In addition to the alterations of the cell membrane composition leading to increased adhesion potential, increased cytokine production, namely MCP-1, was assayed to determine the endothelial cells' ability to attract leucocytes. Supernatant fractions were harvested $24 \mathrm{~h}$ post-fatty acid incorporation. As shown in Fig. 2, trans-18:2-treated endothelial cells (6.6 (SD 0.2) ng/10 6 cells) 


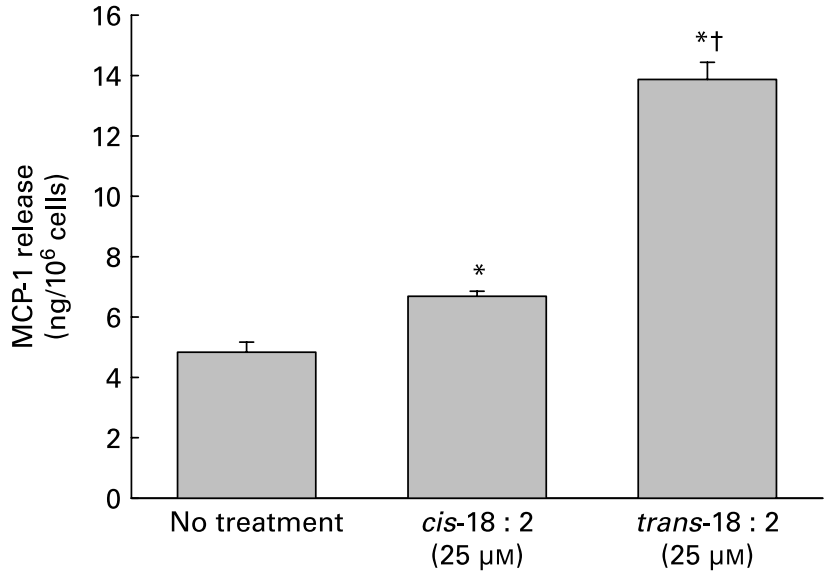

Fig. 2. Effect of cis- and trans-18: 2 fatty acids on monocyte chemoattractant protein-1 (MCP-1) release. Endothelial cells $\left(1 \times 10^{6}\right)$ were incubated with cis- or trans-18:2 fatty acids for $24 \mathrm{~h}$. Subsequently, the cells were washed and then incubated further with endothelial cell basal medium-2 media. Supernatant fractions were harvested $24 \mathrm{~h}$ post-fatty acid incorporation. MCP-1 release was quantified using a Quantikine ELISA kit purchased from $R$ \& D Systems (Minneapolis, MN, USA). Data are means for at least three experiments, with standard deviations represented by vertical bars. The data were analysed using ANOVA $(P<0.001)$ and Tukey's multiple comparison test. * Mean value was significantly different from that of untreated endothelial cells $(P<0.05)$. † Mean value was significantly different from that of the cis-18:2-treated cells $(P<0.05)$.

released roughly two times more MCP-1 than cis-18:2-treated HAEC (13.9 (SD 0.6) ng/106 cells).

\section{Sphingosine-1-phosphate-induced human aortic endothelial} cells chemotaxis

The migratory potential of endothelial cells enriched with $\mathrm{cis}$ $18: 2$ or trans $-18: 2$ fatty acids in response to the bioactive phospholipid SPP is presented in Fig. 3. As expected, SPPdirected migration resulted in cell mobility through the porous membrane under every condition. However, the trans-18:2-treated HAEC (113.3 (SD 7.0) cells/field) were $35 \%$ more motile in response to SPP than those of cis$18: 2$-treated $(83 \cdot 6$ (SD 5.1) cells/field) endothelial cells.

\section{Human aortic endothelial cells capillary morphogenesis}

Endothelial cells stimulated with pro-angiogenic phospholipids and/or protein growth factors characteristically develop into a network of capillary-like structures on Matrigel matrix supports. Fig. 4 (A) depicts a typical representation of the capillary-like structures in response to either SPP or hepatocyte growth factor. The extent of this structural formation was quantified and presented in Fig. 4 (B). Cis-18:2 fatty acid-incorporated endothelial cells mimicked the robust capillary morphogenic response of non-supplemented cells to both SPP and hepatocyte growth factor. HAEC supplemented with trans-18:2 fatty acids demonstrated an impaired ability to form the capillary-like structures on Matrigel supports and exhibited an $80 \%$ reduction in capillary morphogenesis in the presence of SPP (trans-18:2, 8.3 (SD $0.6) v$. cis-18:2, 42.7 (SD 5.5)) or hepatocyte growth factor (trans-18:2, 3.7 (SD 1.2) v. cis-18:2, 22.3 (SD 4.9)). In

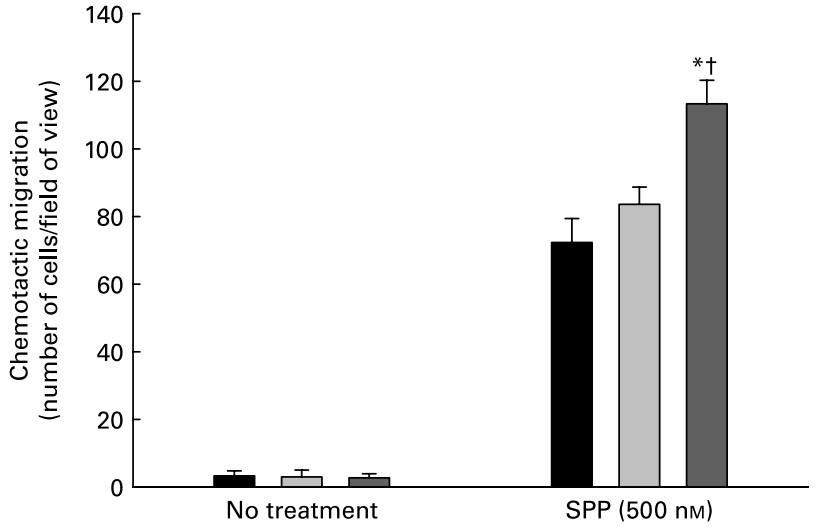

Fig. 3. Effect of cis- and trans-18:2 fatty acids on sphingosine-1-phosphateinduced endothelial cell chemotaxis. Endothelial cells $\left(1 \times 10^{5}\right)$ treated with cisor trans-fatty acids for $24 \mathrm{~h}$ were placed onto an $8 \mu \mathrm{m}$ Transwell chamber insert and incubated for $30 \mathrm{~min}$ at $37^{\circ} \mathrm{C}$ to permit anchoring to the filter. These inserts were then placed into wells containing serum-free endothelial cell basal medium-2 in the presence or absence of sphingosine-1-phosphate (SPP) for $4 \mathrm{~h}$. The migrated cells were fixed in a $5 \%$ formaldehyde solution and subsequently stained with 4',6-diamidino-2-phenyindole $(5 \mu \mathrm{g} / \mathrm{ml})$. Human aortic endothelial cell migration was quantified on an inverted Leica fluorescent microscope by enumeration in three randomly selected fields of view $(200 \times)$ and performed by at least two blinded individuals. ( $\square)$, control; ( $\square$ ), cis-18:2 $(25 \mu \mathrm{M}) ;(\square)$, trans-18:2 $(25 \mu \mathrm{M})$. Data are means for at least three experiments, with standard deviations represented by vertical bars. The data were analysed using ANOVA (no treatment, $P=0.880$; SPP-treated, $P<0.001$ ) and Tukey's multiple comparison test in SPP-treated cells. * Mean value was significantly different from that of untreated endothelial cells $(P<0.05)$. † Mean value was significantly different from that of the cis-18:2-treated cells $(P<0.05)$.

contrast, cis-18:2-treated cells' ability to form capillaries was not significantly different from that of untreated control (SPP, $45 \cdot 3$ (SD 2.1); hepatocyte growth factor, $23 \cdot 8$ (SD 3.6)).

\section{Discussion}

Endothelial cells are critical cellular components in the development and progression of atherosclerosis. In response to inflammatory stimuli, endothelial cells exhibit increased leucocyte adherence, which can culminate in the development of atherosclerotic plaques. In the present study, we set forth to examine the ramifications of trans-fatty acid cellular incorporation on endothelial cell phenotypic and functional characterisation. We found that the incorporation of trans-fatty acids into endothelial cells enhanced the activation state of the cells and leads to altered cell function.

During the present investigation we determined the effects of trans-18:2 fatty acids, which have been shown to have a positive association with $\mathrm{CHD}^{30}$, on endothelial cell function. We found that approximately 2-fold greater levels of trans$18: 2$ fatty acid were enriched in the phospholipids than that of cis-18:2, whereas both trans-18:2 and cis-18:2 were enriched to a similar extent in TAG fractions. This observation suggests that trans-fatty acids were incorporated to a greater extent in cellular membranes. However, the most surprising observation was that the membrane phospholipid incorporation of trans-18:2 was nearly $40 \%$ of total fatty acids. This level of enrichment appears to be excessive. It has been demonstrated that fatty acids are efficiently incorporated in the phospholipids of endothelial cells. In the freshly isolated human umbilical endothelial cells, about $14 \%$ of the total fatty 
(A)
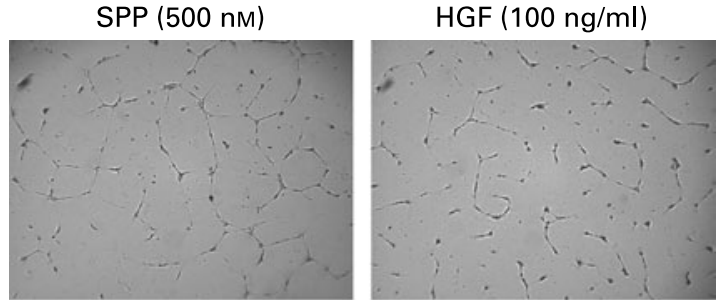

C18: 2 cis
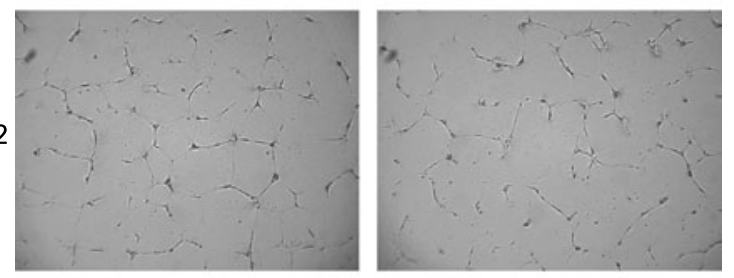

\section{C18: 2}

trans
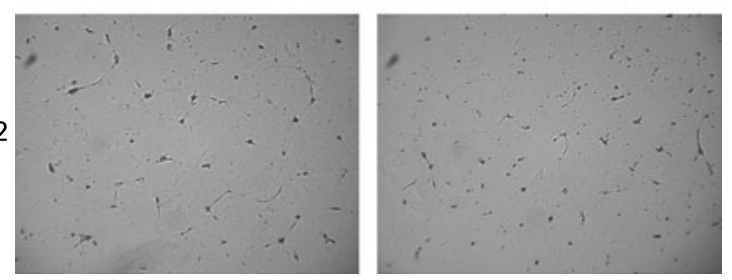

(B)

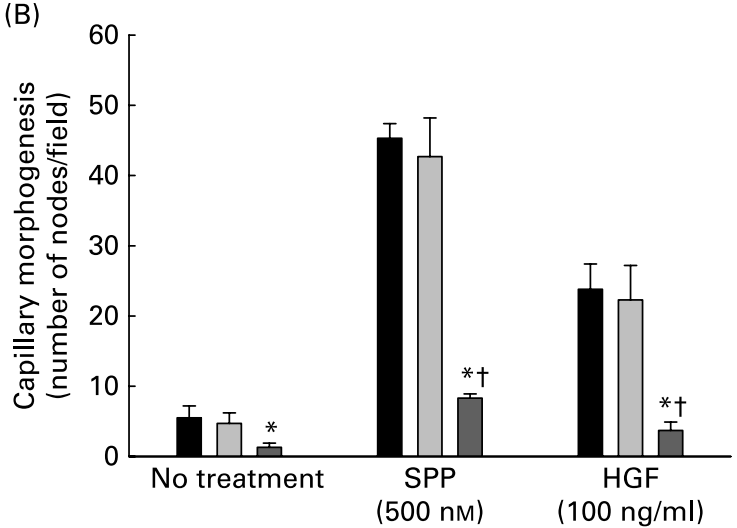

Fig. 4. Effect of cis- and trans-18:2 fatty acids on endothelial cell capillary morphogenesis. Endothelial cells $\left(1 \times 10^{5}\right)$ treated with cis- or trans-fatty acids for $24 \mathrm{~h}$ were placed onto Matrigel-coated wells as described in the Methods section. Human aortic endothelial cells were then supplemented with either sphingosine-1-phosphate (SPP; $500 \mathrm{nm)} \mathrm{or} \mathrm{hepatocyte} \mathrm{growth} \mathrm{fac-}$ tor (HGF; $100 \mathrm{ng} / \mathrm{ml}$ ) and maintained for $16 \mathrm{~h}$ at $37^{\circ} \mathrm{C}$ in the presence of $5 \%$ $\mathrm{CO}_{2}$. (A) Random photomicrographs $(40 \times)$ were captured to assess the extent of the formation of the capillary-like structures. (B) The capillary morphogenesis was quantified by enumerating the number of multicellular

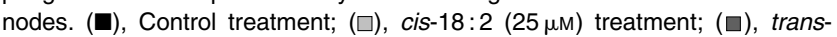
18:2 $(25 \mu \mathrm{M})$ treatment. Data are means for at least three experiments, with standard deviations represented by vertical bars. The data were analysed using ANOVA (no treatment, $P=0.017$; SPP-treated, $P<0.001$; HGF-treated, $P<0.001)$ and Tukey's multiple comparison test. ${ }^{*}$ Mean value was significantly different from that of untreated endothelial cells $(P<0.05)$. † Mean value was significantly different from that of the cis-18:2-treated cells $(P<0.05)$

acids in phospholipids are present as cis-18:1 fatty acid but these levels greatly increased to $22 \%$ on culturing in the presence of fetal bovine serum ${ }^{31}$. Furthermore, in the human endothelial cell line EA.Hy 926, when grown in the presence of $100 \mu \mathrm{M}$-cis-18: 1 fatty acids, incorporation of cis-18:1 in phospholipids was increased to $48 \%$ from a baseline of $24 \%$. Interestingly, adipose tissues of patients with peripheral artery disease contained about $27 \%$ of total fatty acids as trans-fatty acids $(21 \%$ trans- $18: 1+6 \%$ trans$18: 2$ ) and about $13 \%$ of total fatty acids were present as trans-fatty acids ( $8 \%$ trans-18: $1+5 \%$ trans-C18:2) in the atherosclerotic plaques ${ }^{33}$. The trans-fatty acids in human erythrocyte membranes range from 1 to $2 \%$ for trans-18:1 and from 0.2 to $0.4 \%$ for trans-18: $2^{34,35}$. Total trans-fatty acid levels (trans-18:1+ trans-18:2) in adipocytes range from 6 to $9 \%^{36}$. Another study demonstrated that levels of total trans-fatty acids increased in the phospholipid fractions of human serum from $1 \%$ to nearly $4 \%$ on a trans-fatty acid-enriched diet after 4 weeks ${ }^{37}$. The phospholipid fraction from the rat's diaphragm showed accumulation of trans18: 1 up to $5 \%$ after consuming a trans-fatty acid diet for 3 months. These observations indicate that levels of trans$18: 1$ can be increased to a variable proportion in different tissues on consuming trans-fatty acid diets. There are not enough data available in the literature to compare C18:2 trans-fatty acid enrichment in endothelial cells in animals or human subjects on a diet rich in trans-fatty acids. It is clear from these studies using trans-18:1 that endothelial cells can efficiently incorporate long-chain PUFA. In the present study an excessive enrichment of trans-18:2 in endothelial cells appears to be unphysiological, but it remains to be seen if the extent of this enrichment can be achieved in vivo or perhaps in a human system. Furthermore, the present results indicated that endothelial cells incorporated cis- and trans-18:2 fatty acids at the expense of MUFA and SFA content. It is of interest to note that trans-fatty acids, although unsaturated in nature, structurally resemble SFA ${ }^{38}$. SFA typically occupy the sn-1 position, whereas unsaturated fatty acids occupy the sn-2 position in phospholipids. The present results demonstrating that trans-fatty acids are incorporated at the expense of MUFA suggest that trans-fatty acids may be acylated on the sn-2 position of phospholipids, imparting a more saturated and hydrophobic character. Although the determination of sn-1 v. sn-2 incorporation was beyond the scope of the present investigation, more saturated phospholipids, especially those containing trans-fatty acids, are known to attract cholesterol ${ }^{39}$. This phenomenon plausibly alters cell membrane structure, including redefining lipid raft and non-raft regions in size, organisation and composition. Lipid rafts are important for cellular signalling, as they provide docking sites for receptors, co-receptors and mediators including adhesion molecules $^{40}$. Our data also support this interpretation by demonstrating that cell surface expression of adhesion molecules was greatly enhanced in cells grown in the presence of trans-18:2 fatty acids.

HAEC adhesion molecule expression consistently corresponded with endothelial cell adherence to basement membrane components and leucocyte binding to the endothelium. Enhanced adhesion molecule expression is often associated with an inflammatory endothelial cell phenotype. Although the elevated antigenic expression levels in trans-fatty acidtreated HAEC were statistically significant, the increase was modest in comparison with an acute cytokine-stimulated response. However, the present study suggests that long-term exposure of trans-fatty acids to the endothelium could result in a gradual, cumulative chronic state of activation, which could promote the development of atherosclerosis. Additional evidence was found in the notable increase in the MCP-1 
released by trans-fatty acid-treated HAEC. This modest increase in cytokine production, which attracts leucocytes to the primed endothelium, could initiate a cellular infiltration of macrophages, thereby initiating a cascade of plaque formation and intimal thickening. Increased MCP-1 cytokine production has been correlated with the prevalence of atherosclerosis ${ }^{41}$.

Previous studies have demonstrated that SPP exerts proangiogenic effects on endothelial cells, including increases in barrier integrity, chemotaxis and capillary morphogenesis ${ }^{26,29,42,43}$. SPP-induced chemotaxis in endothelial cells was further enhanced in the trans-fatty acid-treated HAEC. Following migration to the site of wound healing, endothelial cells differentiate into vessel linings, a process mimicked in vitro by the assessment of capillary morphogenesis on Matrigel matrix supports ${ }^{29}$. The SPP-induced capillary-like structural formation was significantly impaired in the trans-fatty acid-treated endothelial cells. This endothelial dysfunction could translate into an inability of endothelial cells to repair damaged vessel linings, complicating the pathogenesis of the arterial damage. Furthermore, this process could explain impairment in collateral growth that serves to compensate for an arterial occlusion, especially in the coronary circulation. Thus, trans-fatty acids may play an important role in the development of CHD, and perhaps peripheral vascular disease, through by inhibiting compensatory remodelling.

Endothelial cell apoptosis has been implicated in the progression of atherosclerosis, possibly even contributing to the rupturing of atherosclerotic plaques ${ }^{44}$. A recent report by Zapolska-Downar et al $^{45}$ demonstrated that trans-fatty acids induce endothelial cell apoptosis, which is consistent with an effect of trans-fatty acids on the latter stages of plaque development and/or subsequent rupturing of the plaques. The induction of endothelial cell apoptosis observed by Zapolska-Downar et al. required significantly higher transfatty acid supplementation (up to $5 \mathrm{mM}$ ). Using considerably lower trans-fatty acid-treatments $(25 \mu \mathrm{M})$ under the same $24 \mathrm{~h}$ time frame, we were unable to observe an increase in early signs of apoptosis in HAEC using Annexin V-propidium iodide staining techniques (data not shown). The transfatty acid-induced alterations in endothelial cell activation and function in the present study are clearly not due to the initiation of apoptosis. These alterations implicate trans-fatty acids in triggering the development of atherosclerosis and/or accelerating the progression of the disease. Trans-fatty acids may impart their effect by enhancing intrinsic signalling mechanisms leading to a chronic, pro-inflammatory state.

In an investigation by Kummerow et al. ${ }^{46}$ trans-fatty acid incorporation into HAEC resulted in increased $\mathrm{Ca}$ influx in combination with $\mathrm{Mg}$ depletion. Both linoelaidic (trans$18: 2$ ) and elaidic (trans-C18:1) acids increased incorporation of radiolabelled $\mathrm{Ca}$ intracellularly, whereas stearic $(\mathrm{C} 18: 0)$ and oleic (cis-18:2) acids did not. The authors suggest that this model is representative of endothelial cell calcification, a hallmark characteristic of atherosclerosis, and that dietary trans-fatty acids compound the effect of the relatively low$\mathrm{Mg}$ American diet on this process. While these modest increases in $\mathrm{Ca}$ influx probably result from an alteration in cell membrane fatty acid composition and properties, the effect of free trans-fatty acids on endothelial cell function were not included in their study.
Consumption of trans-fatty acids was correlated with adverse affects on endothelial cell function in vivo ${ }^{19,47}$. Increased plasma concentrations of biomarkers of inflammation, including soluble intercellular adhesion molecule-1, soluble vascular cell adhesion molecule-1 and E-selectin, were associated with the trans-fatty acid content of the diet in the Nurses' Health Study, a cross-sectional investigation of 730 CVD-free women ${ }^{20}$. The authors suggest that this association could explain the significantly greater risk of developing CVD based on the consumption of a high-transfatty acid content diet. While soluble adhesion molecules and inflammatory cytokines correlate with CVD in vivo ${ }^{20,48}$, multiple factors could trigger such a response as a result of the progression of the disease.

In conclusion, the present study provides evidence for a direct effect of trans-18:2 incorporation on the activation status and functional consequence of endothelial cells in vitro, in the absence of stimulation factors found in plasma. Consumption of diets high in trans-fatty acids may induce long-term progressive changes in the endothelium that could trigger the development of CVD. The present study suggests minimising or eliminating the dietary intake of trans-fatty acids might prevent the initiation of a pro-inflammatory state leading to the subsequent development of atherosclerosis. We realised that cis-18:2 and trans-18:2 fatty acids were incorporated to a different extent in endothelial cells when incubated with a similar concentration $(25 \mu \mathrm{M})$ of these fatty acids, which was an unexpected finding. It is possible that the altered biological activities in trans-18:2-treated endothelial cells we observed were simply due to a higher content of fatty acids and independent of their geometric isomers. Further investigation is required to study biological activities related to inflammation in endothelial cells after incorporating similar levels of fatty acids.

\section{Acknowledgements}

The authors wish to thank Mr Colin Terry for the statistical analysis of the data and Dr Karen Spear for her editorial assistance. The contract grant sponsor was Showalter Cardiovascular Fund (contract grant number S-2007-1).

\section{References}

1. Emken EA (1984) Nutrition and biochemistry of trans and positional fatty acid isomers in hydrogenated oils. Annu Rev Nutr 4 339-376.

2. Allison D, Denke M, Dietschy J, Emken E, Kris-Etherton P \& Nicolosi R (1995) Trans fatty acids and coronary heart disease risk. Report of the expert panel on trans fatty acids and coronary heart disease. Am J Clin Nutr 62, 655S-708S.

3. Craig-Schmidt MC (2005) World-wide consumption of trans fatty acids. In First International Symposium on Trans Fatty Acids and Health, p. 4. Copenhagen, Denmark, 11-13 September 2005. http://www.meraadet.dk/gfx/uploads/Summaries\%20reports_eng $\% 20$ side/Trans $\% 20$ fatty\%20acids\%20_\%20symposium.pdf

4. Lichtenstein AH (2000) Dietary trans fatty acid. J Cardiopulm Rehabil 20, 143-146.

5. Kemeny Z, Recseg K, Henon G, Kovari K \& Zwobada F (2001) Deodorization of vegetable oils: prediction of trans polyunsaturated fatty acid content. J Am Oil Chem Soc 78, 973-979. 
6. Willett WC (2006) Trans fatty acids and coronary heart disease - epidemiological data. Atherosclerosis 7, Suppl., 5-8.

7. Kromhout D, Menotti A, Bloemberg B, et al. (1995) Dietary saturated and trans fatty acids and cholesterol and 25-year mortality from coronary heart disease: the Seven Countries Study. Prev Med 24, 308-315.

8. Ascherio A, Rimm EB, Giovannucci EL, Spiegelman D, Stampfer M \& Willett WC (1996) Dietary fat and risk of coronary heart disease in men: cohort follow up study in the United States. BMJ 313, 84-90.

9. Pietinen P, Ascherio A, Korhonen P, Hartman AM, Willett WC, Albanes D \& Virtamo J (1997) Intake of fatty acids and risk of coronary heart disease in a cohort of Finnish men. The AlphaTocopherol, Beta-Carotene Cancer Prevention Study. Am J Epidemiol 145, 876-887.

10. Hu FB, Stampfer MJ, Manson JE, Rimm E, Colditz GA, Rosner BA, Hennekens CH \& Willet WC (1997) Dietary fat intake and the risk of coronary heart disease in women. N Engl J Med 337, $1491-1499$.

11. Stender S, Dyerberg J, Holmer G, Ovesen L \& Sandstrom B (1995) The influence of trans fatty acids on health: a report from the Danish Nutrition Council. Clin Sci (Colch) 88, 375-392.

12. Stampfer MJ, Sacks FM, Salvini S, Willett WC \& Hennekens CH (1991) A prospective study of cholesterol, apolipoproteins, and the risk of myocardial infarction. $N$ Engl J Med 325, 373-381.

13. Ascherio A, Katan MB, Zock PL, Stampfer MJ \& Willett WC (1999) Trans fatty acids and coronary heart disease. $N$ Engl $J$ Med 340, 1994-1998.

14. Katan MB (2006) Regulation of trans fats: the gap, the Polder, and McDonald's French fries. Atheroscler Suppl 7, 63-66.

15. Mensink RP, Zock PL, Kester ADM \& Katan MB (2003) Effects of dietary fatty acids and carbohydrates on the ratio of serum total to HDL cholesterol and on serum lipids and apolipoproteins: a meta-analysis of 60 controlled trials. Am J Clin Nutr 77, 1146-1155.

16. Ascherio A (2002) Epidemiologic studies on dietary fats and coronary heart disease. Am J Med 113, Suppl. 9B, 9S-12S.

17. Kinsella JE, Bruckner G, Mai J \& Shimp J (1981) Metabolism of trans fatty acids with emphasis on the effects of trans, trans-octadecadienoate on lipid composition, essential fatty acid, and prostaglandins: an overview. Am J Clin Nutr 34, 2307-2318.

18. Kummerow FA, Zhou Q, Mahfouz MM, Smiricky MR, Grieshop CM \& Schaeffer DJ (2004) Trans fatty acids in hydrogenated fat inhibited the synthesis of the polyunsaturated fatty acids in the phospholipid of arterial cells. Life Sci 74, 2707-2723.

19. Mozaffarian D, Rimm EB, King IB, Lawler RL, McDonald GB \& Levy WC (2004) Trans fatty acids and systemic inflammation in heart failure. Am J Clin Nutr 80, 1521-1525.

20. Lopez-Garcia E, Schulze MB, Meigs JB, Manson JE, Rifai N, Stampfer MJ, Willett WC \& Hu FB (2005) Consumption of trans fatty acids is related to plasma biomarkers of inflammation and endothelial dysfunction. $J$ Nutr 135, 562-566.

21. de Roos NM, Bots ML \& Katan MB (2001) Replacement of dietary saturated fatty acids by trans fatty acids lowers serum HDL cholesterol and impairs endothelial function in healthy men and women. Arterioscler Thromb Vasc Biol 21, $1233-1237$.

22. van Greevenbroek MM, Voorhout WF, Erkelens DW, van Meer G \& de Bruin TW (1995) Palmitic acid and linoleic acid metabolism in Caco-2 cells: different triglyceride synthesis and lipoprotein secretion. J Lipid Res 36, 13-24.

23. Folch J, Lees M \& Sloane-Stanley GH (1957) A simple method for the isolation and purification of total lipides from animal tissues. J Biol Chem 226, 497-509.
24. English D, Martin M, Harvey KA, Akard LP, Allen R, Widlanski TS, Garcia JG \& Siddiqui RA (1997) Characterization and purification of neutrophil ecto-phosphatidic acid phosphohydrolase. Biochem J 324, 941-950.

25. de Almeida MC, Silva AC, Barral A \& Barral M (2000) A simple method for human peripheral blood monocyte isolation. Mem Inst Oswaldo Cruz 95, 221-223.

26. English D, Kovala AT, Welch Z, Harvey KA, Siddiqui RA, Brindley DN \& Garcia JG (1999) Induction of endothelial cell chemotaxis by sphingosine 1-phosphate and stabilization of endothelial monolayer barrier function by lysophosphatidic acid, potential mediators of hematopoietic angiogenesis. J Hematother Stem Cell Res 8, 627-634.

27. Boguslawski G, Grogg JR, Harvey KA \& English D (2001) Use of DAPI staining for quantitation of cell chemotaxis. Biotechniques 30, 42-44.

28. Harvey K, Welch Z, Kovala AT, Garcia JG \& English D (2002) Comparative analysis of in vitro angiogenic activities of endothelial cells of heterogeneous origin. Microvasc Res 63, 316-326.

29. Harvey K, Siddiqui RA, Sliva D, Garcia JG \& English D (2002) Serum factors involved in human microvascular endothelial cell morphogenesis. J Lab Clin Med 140, 188-198.

30. Lemaitre RN, King IB, Mozaffarian D, Sotoodehnia N, Rea TD, Kuller LH, Tracy RP \& Siscovick DS (2006) Plasma phospholipid trans fatty acids, fatal ischemic heart disease, and sudden cardiac death in older adults: the cardiovascular health study. Circulation 114, 209-215.

31. Lagarde M, Sicard B, Guichardant M, Felisi O \& Dechavanne $M$ (1984) Fatty acid composition in native and cultured human endothelial cells. In Vitro 20, 33-37.

32. Kilsdonk EP, Dorsman AN, van Gent $\mathrm{T} \&$ van Tol A (1992) Effect of phospholipid fatty acid composition of endothelial cells on cholesterol efflux rates. J Lipid Res 33, $1373-1382$.

33. Stachowska E, Dolegowska B, Chlubek D, Wesolowska T, Ciechanowski K, Gutowski P, Szumiłowicz H \& Turowski R (2004) Dietary trans fatty acids and composition of human atheromatous plaques. Eur J Nutr 43, 313-318.

34. Sun Q, Ma J, Campos H, Hankinson SE, Manson JE, Stampfer MJ, Rexrode KM, Willett WC \& Hu FBA (2007) A prospective study of trans fatty acids in erythrocytes and risk of coronary heart disease. Circulation 115, 1858-1865.

35. Lemaitre RN, King IB, Raghunathan TE, Pearce RM, Weinmann S, Knopp RH, Copass MK, Cobb LA \& Siscovick DS (2002) Cell membrane trans-fatty acids and the risk of primary cardiac arrest. Circulation 105, 697-701.

36. Bortolotto JW, Reis C, Ferreira A, Costa S, Mottin CC, Souto AA \& Guaragan RM (2005) Higher content of trans fatty acids in abdominal visceral fat of morbidly obese individuals undergoing bariatric surgery compared to non-obese subjects. Obes Surg 15, 1265-1270.

37. Vidgren HM, Louheranta AM, Agren JJ, Schwab US \& Uusitupa MI (1998) Divergent incorporation of dietary trans fatty acids in different serum lipid fractions. Lipids 33, 955-962.

38. Small DM \& Steiner J (1986) The Physical Chemistry of Lipids. From Aldanes to Phospholipids. Handbook of Lipid Research. New York: Plenum Press.

39. Niu S-L, Mitchell DC \& Litman BJ (2005) Trans fatty acid derived phospholipids show increased membrane cholesterol and reduced receptor activation as compared to their cis analogs. Biochemistry 44, 4458-4465.

40. Brown DA (2006) Lipid rafts, detergent-resistant membranes, and raft targeting signals. Physiology 21, 430-439.

41. Takeya M, Yoshimura T, Leonard EJ \& Takahashi K (1993) Detection of monocyte chemoattractant protein-1 in human 
atherosclerotic lesions by an anti-monocyte chemoattractant protein-1 monoclonal antibody. Hum Pathol 24, 534-539.

42. English D, Welch Z, Kovala AT, Harvey K, Volpert OV, Brindley DN \& Garcia JG (2000) Sphingosine 1-phosphate released from platelets during clotting accounts for the potent endothelial cell chemotactic activity of blood serum and provides a novel link between hemostasis and angiogenesis. FASEB $J \mathbf{1 4}$, $2255-2265$.

43. Garcia JG, Liu F, Verin AD, Birukova A, Dechert MA, Gerthoffer WT, Bamberg JR \& English D (2001) Sphingosine 1-phosphate promotes endothelial cell barrier integrity by Edgdependent cytoskeletal rearrangement. J Clin Invest 108, 689-701.
44. Mallat Z \& Tedgui A (2000) Apoptosis in the vasculature: mechanisms and functional importance. Br J Pharmacol 130, 947-962.

45. Zapolska-Downar D, Kosmider A \& Naruszewicz M (2005) Trans fatty acids induce apoptosis in human endothelial cells. J Physiol Pharmacol 56, 611-625.

46. Kummerow FA, Zhou Q \& Mahfouz MM (1999) Effect of trans fatty acids on calcium influx into human arterial endothelial cells. Am J Clin Nutr 70, 832-838.

47. Mozaffarian D (2006) Trans fatty acids - effects on systemic inflammation and endothelial function. Atheroscler Suppl 7, $29-32$.

48. Kaul D (2001) Molecular link between cholesterol, cytokines and atherosclerosis. Mol Cell Biochem 219, 65-71. 